CASSOWARY volume 5 (1) Januari 2022: 87 - 93

ISSN : 2614-8900

E-ISSN : 2622-6545

Program Pascasarjana Universitas Papua, https://pasca.unipa.ac.id/

\title{
Pengetahuan lingkungan hidup siswa/i dalam menjaga kebersihan lingkungan Sekolah Menengah Atas Negeri 1 Kota Sorong
}

\author{
Oktofianus Demetouw'1), Mulyadi' ${ }^{1)}$, Marlyn N. Lekitoo ${ }^{1)^{*}}$ \\ ${ }^{1)}$ Program Studi S2 Ilmu Lingkungan, Program Pascasarjana, Universitas Papua, Jalan Gunung \\ Salju, Amban, Manokwari, Papua Barat, 98314, Indonesia \\ *Email: merlynpentaloka@gmail.com
}

Disubmit: 06 November 2020, direvisi: 13 Januari 2022, diterima: 26 Januari 2022

Doi: https://doi.org/10.30862/casssowary.cs.v5.i1.68

\begin{abstract}
Knowledge of the environment from 204 students (respondents) has an average score of 249 with an interval scale of 225 - 300 and category 3 of the average score of the questionnaire statement on understanding is 26 and requirements of 223. The level of student knowledge It was concluded descriptively that the environmental knowledge of the students of SMA Negeri 1 Sorong City was high. That of the 204 students as many as $168(82 \%)$ have a total score of 43,097 which the average score is on an interval scale of 225 - 300 with a high category (3) and as many as $36(18 \%)$ have a total score of of 7,667 which the average score is on the interval scale $150-225$ in the medium category (2). A high level of knowledge can be translated by gender for the entire sample studied. Based on table 5.3. the environmental knowledge of male respondents as many as 93 students has a score of 23,014 with an average score of 247 and female as many as 111 students have a score of 27,751 on environmental knowledge with an average score of 247. Both scores gender if the average score is 249 so that it meets category 3 .
\end{abstract}

Keywords: environment knowledge, environment education, senior high school

\section{PENDAHULUAN}

Masalah lingkungan menjadi hal yang sangat sering terdengar pada saat ini dimana banyak sekali kerusakan lingkungan yang terjadi akibat pembalakan liar dan penggunaan sumber daya alam secara berlebihan tanpa ada konservasi yang berkelanjutan, terjadinya peningkatan pemanasan global, dan menurunnya kualitas ekosistem alam. Masalah lingkungan hidup yang terjadi saat ini, baik dari lingkungan global maupun lingkup nasional, sebagian besar bersumber dari perilaku manusia. Halder et al (2012), mengatakan tanta- ngan yang berkaitan dengan degradasi lingkungan dan pembangunan berkelanjutan memiliki implikasi penting yang berhubungan dengan pendidikan dan sekolah. lingkungan hidup berpengaruh besar terhadap ketercapaian tujuan pendidikan. Kurangnya pengetahuan terhadap lingkungan sangat mempengaruhi kerusakan lingkungan dan menjadi ancaman bagi masyarakat, misalnya banjir, tanah longsor, polusi, habisnya sumber air (Azmi, 2017).

Peraturan Menteri Lingkungan Hidup dan Kehutanan Republik Indonesia Nomor P.52/MENLHK/SETJEN 
/KUM.1/9/2019 tentang Gerakan peduli dan berbudaya lingkungan hidup di sekolah. Pendidikan Lingkungan Hidup adalah upaya untuk meningkatkan pengetahuan, keterampilan, sikap, dan aksi kepedulian individu, komunitas, organisasi dan berbagai pihak terhadap permasalahan lingkungan untuk keberlanjutan pembangunan bagi generasi sekarang dan yang akan datang. Sedangkan dalam rangka meningkatkan kualitas lingkungan, perilaku hidup bersih dan sehat di sekolah guna terwujudnya ligkungan sekolah yang sehat, bersih dan nyaman, dan terbebas dari ancaman penyakit perlu dilakukan berbagai upaya penyelenggaraan kesehatan lingkungan sekolah, hal ini dititik beratkan pada keputusan menteri kesehatan nomor 1429/MENKES/SK/XII /2006 tentang pedoman penyelenggaraan kesehatan lingkungan sekolah. Kedua peraturan pemerintah tersebut diatas menandakan bahwa pihak sekolah maupun siswa/i telah dibekali tentang bagaimana memecahkan persoalan dan mejaga kebersihan lingkungan.

Siswa/i SMA Negeri 1 Kota Sorong menyimpan potensi yang cukup besar, di antaranya adalah potensi untuk menjadi manusia yang memiliki keepdulian lingkungan. Meskipun telah ada upaya pendidikan lingkungan secara terintegrasi tetapi belum diketahui apakah keberhasilannya sudah efektif. Berdasarkan kenyataan ini maka perlu dilakukan penelitian untuk mengetahui pengetahuan lingkungan hidup dan perilaku siswa/i dalam menjaga kebersihan lingkungan sekolah menengah atas negeri 1 kota sorong.

Tujuan penelitian ini adalah: Mengetahui Faktor-faktor yang mempengaruhi pengetahuan lingkungan hidup siswa dalam menjaga kebersihan lingkungan SMA N 1 Kota Sorong.

\section{MATERI DAN METODE}

Pengetahuan Siswa/i diukur berdasarkan jumlah skor dari pernyataan pada kuesioner dengan menggunakan skala likrt dan setiap pernyataan memiliki skor. Pengetahuan yang diukur tentang pandangan Siswa/i terhadap Penyelenggaraan Kesehatan Lingkungan Sekolah berdasarkan Peraturan Menteri Kesehatan RI nomor 1429/ MENKES/SK/XII/2006.

Tabel 1. Pengetahuan Siswa/i tentang Kesehatan Lingkungan Sekolah

\begin{tabular}{cllc}
\hline No & \multicolumn{1}{c}{ Variabel } & \multicolumn{1}{c}{ Kriteria } & Skor \\
\hline 1. & Pengertian & Sangat Setuju & 4 \\
& & Setuju & 3 \\
& & Tidak Setuju & 2 \\
2. & Persyaratan & Sangat Tidak Setuju & 1 \\
& & Sangat Setuju & 4 \\
& & Setuju & 3 \\
& & Tidak Setuju & 2 \\
& Sangat Tidak Setuju & 1 \\
\hline
\end{tabular}

Faktor - Faktor yang mempengaruhi Pengetahuan 
Tabel 2. Faktor - faktor yang mempengarungi Pengetahuan Siswa/i

\begin{tabular}{|c|c|c|c|}
\hline No & Variabel & Kriteria & Skor \\
\hline 1. & Lingkungan Sekolah $\left(\mathrm{X}_{1}\right)$ & & \\
\hline \multirow{4}{*}{ a. } & Apakah terdapat program lingkungan & Sangat sering & 4 \\
\hline & hidup/ kebersihan yang diterapkan & Sering & 3 \\
\hline & pihak sekolah & Tidak pernah & 2 \\
\hline & & Sangat tidak pernah & 1 \\
\hline \multirow[t]{4}{*}{ b. } & Apakah anda mengikuti sosialisasi/ & Sangat sering & 4 \\
\hline & penyuluhan / program belajar & Sering & 3 \\
\hline & lingkungan hidup / kebersihan & Tidak pernah & 2 \\
\hline & $\begin{array}{l}\text { lingkungan yang di selenggarakan } \\
\text { pihak sekolah }\end{array}$ & Sangat tidak pernah & 1 \\
\hline 2. & Lingkungan Rumah $\left(\mathbf{X}_{2}\right)$ & & \\
\hline \multirow[t]{4}{*}{ a. } & Apakah terdapat aturan pendidikan & Sangat sering & 4 \\
\hline & lingkungan hidup/kebersihan yang & Sering & 3 \\
\hline & diterapkan rumah & Tidak pernah & 2 \\
\hline & & Sangat tidak pernah & 1 \\
\hline \multirow[t]{4}{*}{ b. } & Apakah anda mengikuti aturan yang & Sangat sering & 4 \\
\hline & diterapkan tentang lingkungan hidup / & Sering & 3 \\
\hline & kebersihan lingkungan di rumah. & Tidak pernah & 2 \\
\hline & & Sangat tidak pernah & 1 \\
\hline 3. & Lingkungan Masyarakat $\left(\mathbf{X}_{\mathbf{3}}\right)$ & & \\
\hline \multirow[t]{4}{*}{ a. } & Apakah terdapat program pendidikan & Sangat sering & 4 \\
\hline & lingkungan hidup/kebersihan yang & Sering & 3 \\
\hline & diterapkan lingkungan Masyarakat & Tidak pernah & 2 \\
\hline & & Sangat tidak pernah & 1 \\
\hline \multirow[t]{4}{*}{ b. } & Apakah anda mengikuti sosialisasi/ & Sangat sering & 4 \\
\hline & penyuluhan / program belajar & Sering & 3 \\
\hline & lingkungan hidup / kebersihan & Tidak pernah & 2 \\
\hline & $\begin{array}{l}\text { lingkungan yang di selenggarakan di } \\
\text { tingkat RT/RW, Kelurahan, Distrik, } \\
\text { Organisasi Masyarakat ataupun } \\
\text { melihat/mendengar publikasi, stasiun } \\
\text { TV }\end{array}$ & Sangat tidak pernah & 1 \\
\hline
\end{tabular}

\section{Populasi Sampling}

Metode yang digunakan untuk mengambil sampel dari populasi menggunakan teknik sampling acak berlapis (stratified random sampling method).

Tabel 3. Perhitungan populasi sampling

\begin{tabular}{lcc}
\hline Kelas & $\begin{array}{c}\text { Jumlah siswa/i } \\
\text { (unit sampel) }\end{array}$ & $\begin{array}{c}\text { Jumlah subyek Proposional 25\% dari } \\
\text { jumlah siswa/i (unit sampel) }\end{array}$ \\
\hline X & 293 & 73 \\
XI & 303 & 76 \\
XII & 266 & 67 \\
\hline Total & 862 & 216 \\
\hline
\end{tabular}

\section{Analisis Data}

Data yang diperoleh akan dianalisis secara kuantitatif dan kualitatif. Analisis data secara kuantitatif akan dilakukan berdasarkan analisis regresi linear berganda menggunakan program SPSS versi 21, untuk melihat hubungan antara variabel yang diamati. Analisis 
kualitatif dilakukan dengan cara mendeskripsikan dan mengintepretasikan hal-hal yang terjadi di lapang.

\section{HASIL DAN PEMBAHASAN}

Hasil kuisioner yang dilakukan terhadap 204 siswa/i SMA Negeri 1 Kota Sorong memiliki pengetahuan lingkungan hidup yang tinggi dalam menjaga kebersihan lingkungan. Hal ini berkaitan juga dengan beberapa faktor penting diantaranya yaitu lingkungan sekolah, rumah dan masyarakat.

\section{Pengetahuan}

Pengetahuan para siswa/i terkait dengan menjaga kebersihan lingkungan di SMA Negeri 1 Kota Sorong disajikan dalam Tabel 4. Data ini menunjukan bahwa pengetahuan lingkungan hidup 204 siswa/i (responden) memiliki nilai rata-rata sebesar 249 dengan skala interval $\geq 225-\leq 300$ dan kategori 3 dari nilai rata-rata skor pernyataan kuisioner tentang pengertian sebesar 26 dan persyaratan sebesar 223. Tingkat pengetahuan siswa/i disimpulkan secara deskriptif bahwa pengetahuan lingkungan hidup siswa/i SMA Negeri 1 Kota Sorong tinggi.

Pengetahuan lingkungan hidup yang dimiliki siswa berpengaruh terhadap sikap siswa dalam menjaga kebersihan lingkungan sekolah (Muliana et al, 2018). Hal ini terlihat pada pene- litian yang terdahulu yang dilakukan pengujian hubungan antara pengetahuan dan sikap siswa yang berada di SMA N 1 Masjid Raya memiliki korelasi postif pada selang kepercayaan 95\% (Muliana et al, 2018).

\section{Lingkungan Sekolah}

Lingkungan sekolah menjadi tempat bagi siswa untuk menghabiskan waktunya dari pagi hingga siang hari. Hal ini menjadi salah satu faktor yang membentuk pengetahuan dan sikap para siswa mengenai kebersihan lingkungan (Arofah dan Pujilestari, 2020). Hasil kuisioner yang dilakukan pada siswa/i SMA N 1 Kota Sorong disajikan pada Tabel 5. Data ini menunjukan bahwa Faktor Lingkungan Sekolah pada siswa/i (responden) sebanyak 204 memiliki jumlah skor pernyataan sebesar 1.246 dengan nilai rata-rata skor 6 sehingga memenuhi kategori 3 dalam skala interval $\geq 6-\leq 8$.

Upaya sekolah dalam meningkatkan pengetahuan siswa/i mengenai kebersihan lingkungan dapat dilakukan dengan berbagai macam kegiatan atau program kebersihan (Kambuaya, 2020). Salah satu contohnya adalah program sekolah sehat yang diterapkan di SDN Kutowinangun 04 Salatiga (Zubaidah et. al. 2017). Kegiatan ini memberikan dampak yang positif bagi para siswa/i.

Tabel 4. Tingkat Pengetahuan Lingkungan Hidup Siswa/i SMA Negeri 1 Kota Sorong

\begin{tabular}{|c|c|c|c|c|c|c|}
\hline \multirow{3}{*}{ Responden } & \multirow{3}{*}{$\sum$} & \multicolumn{2}{|c|}{ Pernyataan } & \multirow{2}{*}{\multicolumn{3}{|c|}{ Pengetahuan }} \\
\hline & & Pengertian & Persyaratan & & & \\
\hline & & $\begin{array}{c}\sum \text { Rata-rata } \\
\text { Skor }\end{array}$ & $\begin{array}{c}\sum \text { Rata-rata } \\
\text { Skor }\end{array}$ & $\begin{array}{c}\sum \text { Total } \\
\text { Skor }\end{array}$ & Kategori & $\begin{array}{c}\text { Skala } \\
\text { Interval }\end{array}$ \\
\hline Siswa/i & 204 & 26 & 223 & 249 & 3 & $\geq 225-\leq 300$ \\
\hline
\end{tabular}

Tabel 5. Faktor Lingkungan Sekolah Siswa/i SMA Negeri 1 Kota Sorong

\begin{tabular}{lccccc}
\hline \multirow{2}{*}{ Responden } & \multirow{2}{*}{$\sum$} & \multicolumn{4}{c}{ Pernyataan Lingkungan Sekolah } \\
\cline { 3 - 6 } & & $\sum$ Skor & $\sum$ Rata-rata Skor & Kategori & Skala Interval \\
\hline Siswa/i & 204 & 1.246 & 6 & 3 & $\geq 6-\leq 8$ \\
\hline
\end{tabular}




\section{Lingkungan Rumah}

Lingkungan rumah merupakan faktor penting yang dapat membentuk karakter siswa (Subianto, 2013). Bagaimana orang tua dan anggota keluarga memberikan teladan bagi para siswa dalam hal menjaga kebersihan akan menjadi sumber pengetahuan dan juga menjadi pembentuk sikap bagi siswa (Makhmudah, 2018). Hasil kuisioner terhadap siswa/i untuk melihat bagaimana pengaruh lingkungan rumah terhadap pengetahuan siswa/i dalam mejaga kebersihan lingkungan ditampilakn pada Tabel 6. Berdasarkan tabel tersebut, terlihat bahwa faktor lingkungan rumah pada siswa/i (responden) sebanyak 204 memiliki jumlah skor pernyataan sebesar 1.390 dengan nilai rata-rata skor 7 sehingga memenuhi kategori 3 dalam skala interval $\geq 6-\leq$ 8 .

\section{Lingkungan Masyarakat}

Interaksi siswa/i dengan masyarakat luas akan menjadi salah satu faktor penentu yang membentuk sikap, pengetahuan dan keparibadian mereka terkait lingkungan hidup (Afriyeni, 2018). Berdasarkan penelitian ini, response para siswa dicatat dan diringkas dalam Tabel 7. Response tersebut menunjukan bahwa Faktor Lingkungan Sekolah pada siswa/i (responden) sebanyak 204 memiliki jumlah skor pernyataan sebesar 1.252 dengan nilai rata-rata skor 6 sehingga memenuhi kategori 3 dalam skala interval $\geq 6-\leq 8$.
Analisis Faktor-Faktor yang mempengaruhi Tingkat Pengetahuan Lingkungan Hidup Siswa/i SMA Negeri 1 Kota Sorong

Berdasarkan Tabel 8 menguji adanya Faktor-Faktor (X) (jenis kelamin, lingkungan sekolah, lingkungan rumah dan lingkungan masyarakat) yang mempengaruhi Pengetahuan Lingkungan Hidup (Y) Siswa/i SMA Negeri 1 Kota sorong secara parsial (individu), peneliti merujuk pada Harlan Johan (2018), dengan kriteria pengujian antara lain : (1) Jika probabilitas (sig) t hitung $<\alpha / 1$ (0.05) maka, H0 ditolak dan H1 diterima, artinya ada pengaruh yang signifikan antara Variabel $\mathrm{X}$ secara parsial terhadap Variabel Y; (2) jika probabilitas (sig) t hitung $>\alpha / 1(0.05)$ maka, $\mathrm{H} 0$ diterima dan $\mathrm{H} 1$ ditolak, artinya tidak ada pengaruh yang signifikan antara Variabel $\mathrm{X}$ secara parsial terhadap Variabel Y. Berdasarkan Tabel 8 untuk nilai $\mathrm{t}$ tabel $(1.9719)<\mathrm{t}$ hitung (15.802) dengan nilai sig $t$ hitung $(0.000)<0.05$, maka dapat dibuat model persamaan regresi yaitu:

$\mathrm{Y}=197.212+0.181 \mathrm{X} 1+0.242 \mathrm{X} 2+$ $4.711 X 3+2.908 X 4$.

Hasil perhitungan uji $\mathrm{t}$ hitung dengan melihat nilai probabilitas (sig) berdasarkan tabel 8 didapat Faktor lingkungan sekolah (X1) memiliki nilai $\operatorname{sig}(0.860)>0.05$ dengan pengujian $\mathrm{H} 0$ ditolak dan $\mathrm{H} 1$ diterima, artinya tidak ada pengaruh yang signifikan antara variabel lingkungan sekolah secara parsial terhadap variabel pengetahuan lingkungan hidup siswa/i dan memiliki arah pengaruh yang positif. 
Tabel 6. Faktor Lingkungan Rumah Siswa/i SMA Negeri 1 Kota Sorong

\begin{tabular}{lccccc}
\hline \multirow{2}{*}{ Responden } & \multirow{2}{*}{$\sum$} & \multicolumn{4}{c}{ Pernyataan Lingkungan Rumah } \\
\cline { 3 - 6 } & $\sum$ Skor & $\sum$ Rata-rata Skor & Kategori & Skala Interval \\
\hline Siswa/i & 204 & 1.390 & 7 & 3 & $\geq 6-\leq 8$ \\
\hline
\end{tabular}

Tabel 7. Faktor Lingkungan Masyarakat Siswa/i SMA Negeri 1 Kota Sorong

\begin{tabular}{lccccc}
\hline \multirow{2}{*}{ Responden } & \multirow{2}{*}{$\sum$} & \multicolumn{4}{c}{ Pernyataan Lingkungan Rumah } \\
\cline { 3 - 6 } & $\sum$ Skor & $\sum$ Rata-rata Skor & Kategori & Skala Interval \\
\hline Siswa/i & 204 & 1.252 & 6 & 3 & $\geq 6-\leq 8$ \\
\hline
\end{tabular}

Tabel 8. Uji t hitung (Secara Parsial (Individu)) dengan model Coefficients ${ }^{\mathrm{a}}$

\begin{tabular}{rlrrrrr}
\hline \multicolumn{2}{c}{ Model } & & \multicolumn{3}{c}{ Coefficients $^{\mathbf{a}}$} \\
& & Unstandardized Coefficients & \multicolumn{3}{c}{ Standardized Coefficients } \\
& & B & Std. Error & Beta & t & Sig. \\
\hline 1 & (Constant) & 197.212 & 12.480 & & 15.802 & .000 \\
& L_Sekolah & .242 & 1.370 & .012 & .177 & .860 \\
& L_Rumah & 4.711 & 1.393 & .250 & 3.380 & .001 \\
& L_Masyarakat & 2.908 & 1.294 & .167 & 2.248 & .026 \\
\hline
\end{tabular}

\section{KESIMPULAN}

Pengetahuan lingkungan hidup 204 siswa/i (responden) memiliki nilai rata-rata sebesar 249 dengan skala interval $\geq 225-\leq 300$ dan kategori 3 dari nilai rata-rata skor pernyataan kuisioner tentang pengertian sebesar 26 dan persyaratan sebesar 223. Tingkat pengetahuan siswa/i disimpulkan secara deskriptif bahwa pengetahuan lingkungan hidup siswa/i SMA Negeri 1 Kota Sorong tinggi.

\section{DAFTAR PUSTAKA}

Afriyeni, Y. (2018). Pembentukan Karakter Anak untuk Peduli Lingkungan yang ada di Sekolah Adiwiyata Mandiri SDN 6 Pekanbaru. PAUD Lectura: Jurnal Pendidikan Anak Usia Dini. 1(2):123-133

Arofah, S.M., Pudjilestari, Y. (2020). Hubungan pengetahuan lingkungan dengan sikap peduli lingkungan pada peserta didik. Prosiding Seminar Nasional Pendidikan Pancasila Dan Kewarganegaraan, Universitas Pamulang. 1(1):97110
Azmi, Fadilla., dan Elfyetti. (2017). Analisis Sikap Peduli Lingkungan Melalui Program Adiwiyata di SMA Negeri 1 Medan, Jurnal geografi, 9 (2) : 125 -132.

Halder, A Bostrom, RE O'Connor, G Böhm, D Hanss, O Bodi, F Ekström. (2012). Causal thinking and support for climate change policies: International survey findings. Global Environmental Change 22 (1), 210-222

Kambuaya, V. T., Sinery, A. S., \& Tokede, M. J. (2020). Realisasi Program Pengelolaan dan Pemantauan Lingkungan (UKL-UPL) di Kota Sorong. Cassowary, 3(2), 101-126. https://doi.org/10.30862/casssowa ry.cs.v3.i2.40

Menteri Kesehatan Republik Indonesia. (2006). Keputusan Menteri Kesehatan nomor 1429/MENKES /SK/XII/2006 tentang pedoman penyelenggaraan kesehatan lingkungan sekolah.

Makhmudah, S. (2018). Penguatan Peran Keluarga dalam Pendidikan Anak. Martabat: Jurnal 
Perempuan dan Anak. 2(2):270286

Muliana, R., Hamama, S. F., \& Zamzami, Z. (2018). Hubungan Pengetahuan Lingkungan Terhadap Sikap Siswa pada Pengelolaan Kebersihan di Sekolah. Jurnal Dedikasi Pendidikan, 2(1), 813.

Peraturan Menteri Lingkungan Hidup dan Kehutanan Republik Indonesia Nomor P.52/MENLHK /SETJEN/KUM.1/9/2019 tentang Gerakan peduli dan berbudaya lingkungan hidup di sekolah.

Subianto, J. (2013). Peran keluarga, sekolah, dan masyarakat dalam pembentukan karakter berkualitas. Edukasia: Jurnal Penelitian Pendidikan Islam, 8(2): 331-354

Zubaidah, S., Ismanto, B., Sulasmono, B.S. (2017). Evaluasi Program Sekolah Sehat di Sekolah Dasar Negeri. Kelola: Jurnal Manajemen Pendidikan. 4(1): 72-82 